\title{
EFEITO ESTUFA E MUDANÇAS CLIMÁTICAS: UM ESTUDO DE CASO NA ESCOLA MUNICIPAL DULCENIDES DOS SANTOS DIAS, COMUNIDADE TERRA NOVA II,
} ZONA NORTE DE MANAUS

\author{
Maria do Rosário Mendonça da Silva ${ }^{1}$ \\ Francisco César Brito Vieira ${ }^{2}$ \\ Augusto Fachín Terán ${ }^{3}$
}

RESUMO: O estudo sobre efeito estufa é importante para compreender melhor as inter-relações entre o homem e o ambiente, suas expectativas, satisfações e condutas. Saber qual é a compreensão dos estudantes do $9^{\circ}$ ano do ensino fundamental sobre o meio ambiente em que vivem através de palestras, atividade extra-classe e pesquisa. Saber o que esse estudante está vivenciando e aprendendo na sala de aula. Este trabalho teve como objetivo didático compreender o entendimento que $\mathrm{o}$ indivíduo percebe e promove sobre a sensibilização, bem como o desenvolvimento do sistema e a formação de um conceito e transformação do ambiente em que vive. Assim, espera-se contribuir com o desenvolvimento de um ensinoaprendizagem mais eficiente e voltado a realidade. A pesquisa foi realizada com estudantes do 90 ano do ensino fundamental da Escola Municipal Dulcenides dos Santos Dias, situada na Zona Norte de Manaus. Para isso utilizou-se o método Hermeneutico dialético e a pesquisa participante, através da utilização do recurso de reportagens, imagens de impactos ambientais, entrevistas, vídeos e debate. Os procedimentos de análise foram qualitativos e quantitativos com uso de tabelas e gráficos. Os resultados mostram que no

\footnotetext{
${ }^{1}$ Professora do 1 ao 5 , da rede pública municipal. Formada em educação e pós graduada em gestão escolar e psicopedagogia pelo IDAAM / Estácio de Sá.

${ }_{2}^{2}$ Mestre em Educação e Ensino de Ciências na Amazônia. Professor em Ciências do 6 ao 9 ano da rede pública municipal.

${ }^{3}$ Dr. Em Educação ambiental, professor e coordenador do Programa de Pós-Graduação em Educação e Ensino de Ciências na Amazônia (PPGECA), Mestrado Profissional em Ensino de Ciências na Amazônia, pela Universidade Estadual do Amazonas-UEA.
} 
conceito formado pelos alunos, eles não se vêem como parte responsável pelo efeito estufa e como modificadores do clima, eles acreditavam que o meio ambiente deve ser utilizado para o homem, mas de forma racional. Após a participação desta atividade, os estudantes passaram a entender melhor o papel do ser humano nas mudanças climáticas e sua complexidade, compreendendo melhor sua participação e intervenção no meio em que vivem.

Palavras chaves: Aquecimento. Efeito estufa. Estudantes.

\section{INTRODUÇÃO}

O tema sobre efeito estufa e aquecimento global não inserido nos Parâmetros Curriculares Nacionais (PCN's) das escolas, isto surgiu diante da preocupação com a formação de atitudes relacionadas a esta temática. A escola proporciona mudanças de atitudes de seus alunos com relação ao ambiente, pois, tem procurado através de diferentes disciplinas, proporcionar informações relativas as questões ambientais e especificamente relacionadas ao clima. O homem está constantemente interferindo sobre o meio com o objetivo de sanar suas necessidades. Cada indivíduo percebe, reage e responde de forma diferente, frente às ações sobre o meio.

Os conceitos formados ou suas manifestações são, portanto resultado das percepções, dos processos cognitivos, julgamentos e expectativas de cada indivíduo. Embora nem todas as manifestações psicológicas sejam evidentes, são constantes, e afetam nossa conduta, na maioria das vezes, inconscientemente. Dessa forma, o estudo sobre efeito estufa é de fundamental importância para que possamos compreender melhor as inter-relações entre o homem e o ambiente, suas expectativas, satisfações e insatisfações, julgamentos e condutas (FAGGIONATO, 2002).

Saber como os alunos de ensino fundamental conceituam os problemas ambientais em que vivem, suas fontes de satisfação e insatisfação é de fundamental importância, pois possibilita a realização de um trabalho com bases locais, partindo da realidade do público alvo, de um plano micro para um plano o macro. Este trabalho teve como estratégia didática não apenas o entendimento do que o indivíduo percebe (conceito pessoal), mas promover a sensibilização, bem como o desenvolvimento do sistema de percepção e compreensão do ambiente nos estudantes em questão. Assim, espera-se 
contribuir com o desenvolvimento de um ensino-aprendizagem mais eficiente e adequado à realidade.

Segundo Ferrara (1999), diversa são as formas de se estudar as questões ambientais: questionários, palestras, fotos, vídeos e mapas. A questão ambiental pode ser entendida como a representação (oral, gráfica e corporal) do ambiente, onde o lugar é o veículo de acontecimentos emocionalmente fortes ou percebidos como um símbolo (TUAN, 1974). Segundo J. Filho et al (1995), a escola é o meio ideal para o desenvolvimento de uma consciência sobre um determinado assunto. Por meio do estímulo dos professores, os alunos poderão refletir sobre temas atuais, passando de agentes passivos a ativos, visando considerar sua história, valorizar o local onde moram e preservar o meio ambiente.

\section{HISTÓRICO DA COMUNIDADE}

A Escola Municipal Dulcenides dos Santos Dias, está situada no setor norte do bairro Terra Nova II. O local onde se encontra a escola foi originalmente um balneário particular de final de semana. Dizia-se proprietária do terreno uma senhora de nome Dorotéia. $\mathrm{O}$ acesso até o local era feito por uma estreita estrada de barro, e toda a área era recoberta por uma fechada vegetação nativa. Havia um lindo igarapé de águas transparentes e relativamente profundas, denominado "Gleba dos Passarinhos".

A partir de 1991, toda a área que constitui hoje o bairro Terra Nova II, foi invadida por pessoas que sem ter um teto para morar, enfrentaram toda sorte de dificuldades em busca de um pedaço de terra onde pudessem construir um barraco e abrigar suas famílias, tendo na frente do movimento de invasão, a Irmã Helena e o Sr. Francisco Biapino, que posteriormente tornou-se o primeiro presidente da Associação Comunitária do bairro. Nesse ínterim, o antigo balneário já havia sido abandonado e o local passou a ser usado pelos novos moradores como fonte de água potável e local para lavagem de roupas.

Com o tempo, a margem direita do referido igarapé foi desmatada e transformada em um campo de futebol, único centro recreativo dos moradores do lugar, onde aos domingos, havia sempre disputas acirradas de times da redondeza. No entanto, e apesar de ser um local de recreação para os moradores, o campo passou a ser também, local de 
desova de cadáveres humanos e boca de fumo, passando a preocupar as pessoas de bem que moravam próximas do referido campo.

Em 29 de janeiro de 1998 a Associação Comunitária presidida pelo Sr. Antônio Valdenir, percebendo a carência de escolas no bairro, uma vez que as existentes não atendiam a demanda da comunidade, e embasado no Projeto "Toda Criança na Escola", encaminhou ofício à Prefeitura Municipal de Manaus, solicitando a abertura de novas vagas, propondo a utilização das instalações do Centro Social da Igreja Católica, minimizando assim o problema da marginalidade e atendendo aos anseios da comunidade.

A Escola compõe-se de dois pavilhões: o primeiro e o terceiro abrigam onze salas de aula, um laboratório de informática e uma secretaria. No segundo pavilhão, uma biblioteca, uma sala para professores, uma sala de coordenação pedagógica todas climatizadas. O segundo pavilhão abriga a cantina, cozinha, depósito de merenda, um amplo refeitório, a sala da diretoria, laboratório de ciências e matemática, sala dos professores, sala dos técnicos e a biblioteca.

A atividade foi realizada especificamente com trinta e dois (32) estudantes de uma turma do $9^{\circ}$ ano do ensino fundamental do turno noturno, onde se concentram adolescentes, jovens e idosos. Primeiramente, a abordagem foi feita através da construção de frases relacionadas sobre o conceito "efeito estufa", o acompanhamento foi feito pelo autor do presente trabalho com os estudantes em questão. As respostas do questionário escrito foram analisadas estatisticamente e dispostas em gráficos para melhor visualização. Posteriormente foi dada uma palestra sobre mudanças climáticas de forma pré-verbal, isto é, apenas observar o que os estudantes queriam revelar dos seus valores sem, no entanto, exigir suas expressões verbais. Para isso foi utilizado o recurso de reportagens, entrevistas e fotos de jornais e revistas, quando os mesmos estudantes selecionados foram convidados a apresentarem seus trabalhos durante a semana do meio ambiente na escola, com a finalidade de demonstrar tudo àquilo que haviam assimilado sobre a realidade das mudanças climáticas, ou tudo aquilo que estivesse relacionado sobre o seu meio ambiente local. A atividade foi direcionada de forma a dirigir a percepção dos alunos ao que eles representariam como sendo efeito estufa.

Foram utilizados vários recursos, tais como vídeos, entrevistas, mapas e fotos, num total de noventa e duas (92). Para o maior esclarecimento de parâmetros de 
comparação com maior discernimento entre o material produzido, solicitou-se o registro dos locais ou situações que na percepção dos alunos era considerado causas que contribuem para o aumento da temperatura, aquecimento e o efeito estufa. Outros recursos utilizados foram às recortadas de revistas e jornais, onde os estudantes foram orientados a colocar no papel a imagem que tinham na mente a respeito de degelo, desmatamento, desertificação e fazer uma representação (desenho).

Após essas etapas foi realizada uma aula expositiva sobre o tema "efeito estufa e mudanças climáticas, consequências para a humanidade e o meio ambiente", onde os resultados obtidos pela classe foram discutidos de maneira que os estudantes puderam perceber alguns erros que cometeram ao conceituar efeito estufa. Todos os participantes da pesquisa tiveram acesso aos trabalhos dos demais colegas e durante a exposição dos trabalhos por ocasião da semana do meio ambiente, realizada no período de $1^{\circ}$ a 05 de junho, nas dependências da Escola Municipal Dulcenides. Foram montados painéis e os "apresentadores" tiveram a oportunidade de explicar a sua produção e as razões que o levaram a trabalhar essa temática. Depois da exposição de cada apresentador, foi concedido um tempo para discussão de forma a estimular o diálogo entre os estudantes da escola e comunidade, com o intuito de promover ações que minimizem as causa do efeito estufa.

\section{ANÁLISE E DISCUSSÂO DOS RESULTADOS}

Os estudantes foram solicitados a definirem o que é efeito estufa, e as respostas predominantes foram: "Efeito estufa, é um lugar todo fechado com plantas dentro", “Efeito estufa, acontece quando se extrai material da floresta, como as árvores e minerais, e nós temos que preservar muito bem", "Efeito estufa, é um local que fica muito quente quando se faz queimada”. Os conceitos apesar de variados, mas seguem a mesma linha, todos os estudantes lembraram do meio ambiente natural, mas não viram o ser humano como agente transformador e influenciador desse meio.

Dos materiais apresentados fotos, vídeos, entrevistas e mapas, observou-se algumas (onze) categorias, cujos percentuais de quantidade está na Tabela 1 abaixo. 
Tabela 1. Categorias e percentual responsável pelo efeito estufa e mudanças climáticas.

\begin{tabular}{cc}
\hline Categorias & $\%$ \\
\hline Desmatamento (desflorestar) & $21,75 \%$ \\
Queimadas & $17,28 \%$ \\
Poluição das fábricas & $16,02 \%$ \\
Poluição dos carros & $13,25 \%$ \\
Outros paises & $9,67 \%$ \\
O homem & $8,09 \%$ \\
Retenção dos raios do sol & $6,16 \%$ \\
Falta de chuva & $3,87 \%$ \\
Impermeabilização do solo & $3,22 \%$ \\
Construções de casas & $2,58 \%$ \\
Exploração dos recursos naturais & $1,33 \%$ \\
\hline
\end{tabular}

Essa exposição inquieta e começa a gerar conflitos a partir do momento que os alunos percebem essa trama socioambiental, uma maior participação da sociedade, empresários, escola e políticos, pois o ambiente é fonte de vida, e, portanto, direito de todos, como assegura o artigo 225, em seu parágrafo primeiro da Constituição Federal, onde estabelece o caráter público do meio ambiente.

Todos têm direito ao meio ambiente ecologicamente equilibrado, bem de uso comum do povo e essencial à sadia qualidade de vida. E é função do Poder Público e da coletividade o dever de defendê-lo e preservá-lo para as presentes e futuras gerações. (CONSTITUIÇAO FEDERAL, 2008).

No material exposto há ênfase de denunciar contra os que insistem em desmatar, queimar e poluir, apesar de muitos vivenciarem essa pratica. Essa denúncia no material fez-se explícita também nos debates, em que um aluno argumenta: "Esse povo não sabe que esta prejudicando a nos mesmo". Esse é o único momento em que se deslumbra a 
educação como uma relação humana, estabelecendo entre as pessoas uma relação de indicar o culpado, longe de qualquer atuação colaborativa. Isso faz com que o meio ambiente urbano supere a simples caracterização física ou técnica da infra-estrutura, para assumir uma dimensão educacional e cultural indiscutíveis. Foram muitos os relatos focalizados nos aspectos de agressão ao meio ambiente.

Muitas imagens de florestas e matas virgens, outras de plantações e quintais com árvores frutíferas e jardins bem cuidados registraram um meio ambiente ideal. Com relação às fotos de áreas desmatadas uma aluna explicou no debate

Essa era uma área de floresta fechada, mas as pessoas invadiram e desmataram tudo para construir suas casas, a polícia apareceu e expulsou todo mundo, mas o estrago já estava feito e agora essa área ficou assim cheia de casas (Estudante Jocilene 27 anos, bairro Monte Pascoal, 2009).

É importante analisar o potencial das falas e comunicar a importância do clima para a população em geral. Nada mais óbvio em uma cidade que se desenvolveu entrecortada por rios e igarapés e comumente ouvimos sobre desmatamento e queimadas. Isso é bem evidente na fala do estudante Douglas.

Aqui era muito legal antes das outras invasões, hoje tem muito lixo no igarapé do passarinho, mau cheiro na água que vem das e ruas escorrem pra lá, ainda tem gente que nesta época de verão queima lixo todo dia e a gente não consegue nem respirar, arde os olhos e dá tosse. (24 anos, bairro Monte Pascoal, 2009).

Algumas imagens lembram a situação do bairro e das casas na época da invasão, muitas de madeira, pequenas e em geral de um ou dois cômodos. Ruas asfaltadas e cheias de buraco que não entra carros nem ônibus. Algumas fotos mostram a estrutura das casas e estabelece bem o limite da invasão, um verdadeiro discenso. A fala da estudante S. , retrata esse ambiente.

Eu fotografei o quintal do meu vizinho porque ele estava varrendo as folhas, estava todo sujo. Depois ele juntou tudo e em vez de botar num saco, ele queimou todas as folhas, então eu falei pra ele que estava enchendo de fumaça em casa, e ele me respondeu que era mais rápido e dava menos trabalho. (16 anos, bairro Terra Nova, 2009)

Foram apresentadas imagens de fábricas com impermeabilização e poluição, porém a interpretação dos estudantes foi diferente como se percebe na fala da estudante 
Mônica (28 anos, Monte Sinai, 2009), "As fábricas da cidade tem uma estrutura muito bonita e jardins bem cuidados e verdes, mas não sabem como conter a fumaça”. Como se pode observar a relação que os alunos fazem sobre o efeito estufa e sua relação com a poluição do ar causada pelas queimadas na invasão ou pelas fábricas dos arredores.

Com menor participação, algumas fotos mostraram a preocupação com 0 surgimento de moradias e condomínios, e diante disto era preciso desmatar. Os estudantes relataram que queriam conservar essa natureza agora para que seus filhos e netos tenham um clima melhor, para que no futuro eles não digam que seus pais tiveram a oportunidade e não fizeram nada.

Foi pedido aos estudantes participantes da pesquisa para desenharem a imagem que tinham na mente sobre o planeta terra hoje e no futuro, fazer um mapa mental. Os mapas mentais $(n=32)$ indicaram 20 amostras $(62,5 \%)$ com elementos naturais como desenhos de árvores, animais e rios; e 12 amostras (37,5\%) indicaram elementos urbanos, como edificações, lixo, meios de transporte e o ser humano, além de elementos naturais.

Aqueles estudantes que no mapa mental não evidenciaram o ser humano como parte do meio, após a realização do debate com interpretação e comentários das fotografias, passaram a ter uma visão diferente e mais coerente com a realidade. Isso pode ser observado no conceito sobre efeito estufa formado por escrito pelo aluno J. 16 anos, antes do debate e após o debate. Seu conceito antes do debate era

\footnotetext{
O efeito estufa acontece quando não preservamos o ambiente e tudo da natureza, floresta, rios e animais, e após o debate: $O$ efeito estufa tem ação direta do homem e sobre o homem e a natureza e tudo que ele ocasiona, e nós mesmos fazemos parte desse meio ambiente, e precisamos preservar ele porque sem ele não tem vida no planeta. (J. 16 anos, Terra Nova, 2009).
}

Os trabalhos dos estudantes constituem o documento que confere validade científica à pesquisa, ao mesmo tempo em que são signos, representação dessa percepção ambiental dos estudantes. Assim foi possível captar a representação que se tem sobre efeito estufa e aquecimento global no cotidiano deles. Nos trabalhos a maior preocupação foi em retratar ambientes transformados, resultantes da ação e interferência humana. Já os mapas mentais se referiram na sua maioria a ambientes naturais. Concluise que a primeira imagem que vem na mente dos estudantes sobre efeito estufa, está 
relacionado ao ambiente sem interferência humana. Mesmo sem o conhecimento técnico - cientifico, percebe-se o papel que as florestas têm, é um papel fundamental na regulação de temperaturas e consequentemente do clima.

Os países que tem florestas devem conservá-las, e aqueles com baixa densidade florestal necessitam de reflorestamento, já que as árvores, limitadamente, conseguem manter lençóis subterrâneos, retirar energia da terra e umidificar o ar, regulando as temperaturas e o clima dos ecossistemas terrestres. (GOMES DOS SANTOS, BENTO, CORDEIRO, 2007, p. 59).

Jacobi (2000), em sua pesquisa de percepção, também obteve como resultado um índice muito baixo de preocupação com a poluição do ar; as principais referências de desejo de urbanização referiram-se ao asfaltamento das ruas e acesso a esgoto; os indivíduos participantes também destacaram a importância de mudar a atitude dos que desmatam, queimam em locais impróprios e poluem.

\section{CONSIDERAÇÕES FINAIS}

Como resultado obtido nessa atividade sobre efeito estufa, foi notório a ampliação do conhecimento e interesse por essa problemática ambiental e mudanças no comportamento e atitudes. Para esse grupo de estudantes, formar um texto ou falar sobre mudanças climáticas tornou-se algo mais fácil e coerente com a realidade vivida, já que eles passaram a se ver como parte integrante desse processo. Para trabalhar a educação é preciso repensar nossa maneira de conduzir as mudanças, reformando nosso pensamento, atitudes e adotando uma postura de ordem cultural e metodológica. É preciso reabilitar o que a fragmentação dos saberes tem causado ao ser humano, a natureza e a realidade. Trata-se de promover uma forma de pensar capaz de recompor o conhecimento dividido e de gerar uma nova ética na articulação entre teoria e prática, ação e saber, com o intuito de criar uma nova solidariedade entre os seres humanos. Isso deve partir da consciência dos professores, em enfatizar os problemas ambientais para os seus estudantes, ensinar e exercitar a postura correta diante das questões relacionadas ao meio ambiente, impactos gerados e consequências de nossas ações, saindo do discurso, dos livros didáticos e utilizando a própria realidade para e com os estudantes. 


\section{REFERÊNCIAS BIBLIOGRÁFICAS}

BARBIERI, José Carlos. Desenvolvimento e meio ambiente - as estratégias de mudanças da agenda 21. 7. ed. Petrópolis, RJ: Vozes, 2005.

CARVALHO, Isabel Cristina de Moura. Educação Ambiental: A formação do sujeito ecológico. 4. ed. São Paulo: Cortez, 2008.

DA VEIGA, José Eli. Aquecimento Global - frias contendas científicas. (org) - São Paulo: Editora SENAC São Paulo, 2008.

DELIZOICOV, Demétrio. ANGOTTI, José André. PERNAMBUCO, Marta Maria. Ensino de Ciências: fundamentos e métodos. São Paulo: Cortez, 2002.

FAGGIONATO, Sandra. Percepção ambiental: material de apoio - textos, 2002. Disponível no site http://educar.sc.usp.br/biologia/textos/m_a_txt4.html. Acessado em 13. dez. 2008.

FARIS, Stephan. Mudança Climática. As alterações do clima e as conseqüências diretas em questões morais, sociais e políticas. Trad. Ana Beatriz Rodrigues. Rio de Janeiro: Elsevier, 2008.

FERRARA, Lucrecia D' Alessio. Olhar Periférico: informação, linguagem, percepção ambiental. São Paulo: Edusp, 1999.

FILHO, J.R.M., PEREIRA, E.D., ARAÚJO, M.L. Educação Ambiental na escola: uma experiência na escola estadual de $\mathbf{1}^{\circ}$ grau Liberdade. Monografia. NUMA/UFPA, 1995.

GOMES DOS SANTOS, Aparecido. BENTO, Antônio Henrique, CORDEIRO, José Pedro. Observando a Natureza. Manaus: EDUA, 2007.

HIGUCHI, Maria Inês Gasparetto. HIGUCHI, Niro. A floresta amazônica e suas múltiplas dimensões: Uma proposta de educação ambiental. Manaus: INPA; CNPQ, 2004.

JACOBI, Pedro Roberto. Cidade e meio ambiente: percepções e práticas em São Paulo. $1^{a}$ ed. São Paulo: Annablume, 2000.

NARDI, Roberto. Questões atuais no ensino de ciências. (org) - São Paulo: Escrituras Editora, 1998.

Secretaria da Educação Fundamental / Ministério da Educação. Parâmetros Curriculares Nacionais: meio ambiente e saúde. 3ª edição. Brasília: A Secretaria, 2001.

SOARES, Terezinha de Jesus. Efeito Estufa - A Amazônia e os aspectos legais. Manaus: EDUA / INPA, 2007.

TUAN, Y.F. Topofilia: Um estudo da Percepção, atitudes e valores do meio ambiente. São Paulo, SP: Difel, 1974.

VAL, Adalberto Luís. MENDES DOS SANTOS, Geraldo. GEEA: Grupo de Estudos Estratégicos Amazônicos. (orgs) Manaus: INPA, 2007. 